\title{
INTEGRATED APPROACH COMBINING DIRECT SURVEY AND OBSERVATION IN DAMAGE ANALYSIS IN CASE OF SOIL SETTLEMENT
}

\author{
M. C. Giangregorio ${ }^{1}$, N. Cortinovis ${ }^{2}$, G. Cardani $^{1}$, D. Coronelli ${ }^{1}$ \\ ${ }^{1}$ Dept. of Civil and Environmental Engineering, Politecnico di Milano, Piazza Leonardo da Vinci 32, 20133, Milano, Italy - \\ \{mariachiara.giangregorio, giuliana.cardani, dario.coronelli \}@polimi.it \\ 2 Politecnico di Milano, Piazza Leonardo da Vinci 32, 20133, Milano, Italy - \\ nicole.cortinovis@mail.polimi.it
}

Commission VI, WG VI/4

KEY WORDS: Architectural heritage, geometrical survey, damage analysis, three-dimensional limit analysis, soil settlements

\begin{abstract}
:
Nowadays, different methods are used to study historical masonry buildings. Among these, for the study of architectures with complex geometry, the effectiveness of an integrated approach, that is a method of analysis combining different disciplines, is increasingly evident.

The aim of this paper is to show the importance of combining direct observation with structural analysis in order to understand the level of safety in buildings with composite geometries.

This paper describes the analysis executed in the XX century parish church of San Bernardino in Sesto Calende (Va), which displays serious cracks and damage caused by soil settlements.

The integrated approach starts with historical analysis, by consulting all available documents and drawings. To understand the geometry of the structure a new survey has been made and a three-dimensional digital representation was modeled, by which better deriving the weight of all the elements in the construction, and to find the correct actions and thrust on arches, columns, bases and foundation. All this data was used in the structural analysis based on the static method of limit analysis. For the material behavior the model proposed by J. Heyman (1966) is used, considering the "no tension" failure criterion. The static theorem of minimum reactions for settled states enunciated by M. Como (2010) is employed for the analysis of soil settlement effects on the building's response.
\end{abstract}

The work shows how direct survey of geometry and damage of a complex building has an effective importance in the structural analysis to ensure Cultural Heritage preservation and safety.

\section{INTRODUCTION}

The difficulties in analysing complex historical buildings are mainly due to the lack of adequate knowledge of the entire building system. The study of historical masonry architecture must be based on a knowledge of the structures, the materials, the transformations over the centuries, the damage, the repair interventions and not least the correct geometry of the building, with the purpose of preserving it in safety conditions.

In this paper the method reported aims to provide an initial analysis of the structural response and of the state of conservation of complex buildings, thanks to an integrated approach. In order to demonstrate the relation between observation in situ and structural analysis in the study of Architectural Heritage, an application to the Church of S. Bernardino in Sesto Calende (Va) is shown, but it can be easily extended and generalized to many buildings characterized by similar systems.

The study proposes a preliminary assessment of the structural safety of the church, identifying the possible causes of the current damage and which can be still active. This assessment is combined with the structural analysis based on the static method of Limit Analysis.

For the geometry of the church, thanks to modern technologies, digital modelling presents a high level of detail. However, data redundancy is not always useful for structural analysis. Also, for the failure criteria some simplifications in the behaviour of the material are adopted.
With this procedure it will be possible to define an effective intervention plan, which does not endanger the survival of the building, and which should be preceded by a plan for diagnostic investigation and the evaluation of the damage evolution thanks to a structural health monitoring system currently in progress.

\section{INTEGRATED APPROACH: RELATION BETWEEN DIFFERENT DISCIPLINES}

The method divides the research into different parts, as follows: i) Study of Historical documentation and drawings, ii) Geometrical Analysis, iii) Damage Observation, iv) Structural health monitoring system and v) Structural Analysis. Historical documentation allows to understand different aspects of the construction, sometimes the first drawings with construction details or subsequent surveys, technical reports with descriptions of changes or damages and repairs to the building. Present surveys can provide more details about the geometry, in order to construct a three-dimensional digital modelling. This allows to obtain the dead loads that characterize these buildings. Thanks to a CAD software it will be simpler to obtain the volumes of this complex building. This model will be used in structural analysis thanks to a combination of drawing and calculation tools, using spreadsheet calculations and in a more advanced way Matlab scripts. 
For the structural analysis the static method of Limit Analysis is used, under simplifying hypotheses. The effectiveness of the analytical method in three-dimensional statics is demonstrated in the study.

In order to understand the effective response of the structure, present survey has again an important role. The inspections during surveys allowed to better define the structure of the building where this is not normally accessible, in order to conclude the geometric analysis, to understand the configuration of the system. On the basis of this, the static model is based on the division of the system in its structural members, each with the pertaining load transfer action.

The current crack pattern, compared with the historical one allows to understand what are the repeated damage patterns, and if there is a new mechanism.

Comparing the different results allows to better understand the causes of damage, with the purpose of reducing their effects, defining a threshold damage level and scheduling more accurate maintenance.

The crack pattern is observed also with the aim of defining the data for the structural analysis. Thus, the stress states and related internal forces are defined for the members. The cracked arcade walls in particular are modelled proposing a simple but new approach. The static theorem of settled states (Como, 2010) is used to define a condition of full development of the soil settlement effects on the superstructure and study its structural safety. In relation to Finite Element (FEM) analyses the proposed approach studies the role of each structural element in the system, thus providing a synthetic evaluation, compared to the local results in terms of stresses and strains of a continuum. Taking into account limit conditions is more effective for the study of strengthening than elastic analyses, and faster and less cumbersome than non linear FEM analyses.

The systematic comparison between the analysis carried out using the numerical model and the experimental observations of the existing building is part of the innovative integrated approach.

\section{DESCRIPTION OF THE CASE STUDY: THE CHURCH OF ST. BERNARDINO IN SESTO CALENDE}

The troubled history of the construction of the church was reconstructed, through the consultation of the documents present in different archives. It was possible to draw up a chronology of events, divided into its design and construction phases.

The parish Church of Saint Bernardino was built in 1905, after the demolition of a XV century parish Church in 1904, due to apparent fears from cracks attributed to soil settlements. Both buildings were built not far from the river Ticino.

The first stone of the church was laid on July 2, 1905 by the Archbishop of Milan Andrea Carlo Ferrari (Cardani, 2018). The church was finished and blessed in 1912, after 7 years of work, (Cardani, 2018).

Between 1924 and 1930 the new bell tower was constructed, detached from the church on the South side, (Figure 1a), as the first bell tower, located on the North side, showed signs of failure during the construction works.

A few years later, in 1937, the façade back wall was completed with an added structural arch bearing the new organ, designed by the engineer $V$. Vittadini.

Until then the church had a rustic façade. In 1960, the same engineer Vittadini presented the drawings for the construction of an added reinforced concrete façade, with a self-supporting structure. The new external façade was finished in 1963 (Figure $1 b)$.
The church also presents, only on the North side, two different chapels built in different periods: the first chapel, built in 1949 and the second built in 1964.

The study shows a new geometric survey, more than 60 years later. The new survey was carried out through the analysis of the historical documents, the descriptions of the engineer Vittadini in 1930 (Cardani, 2018) and the comparison between measurements present on the original drawings with measurements taken on site using simple instrumentation. The observation of the building combined with a new survey were fundamental to understand the configuration of the whole system. The building with East - West orientation is characterized by a longitudinal plan with three naves (length about 32,84 m), without transept, a semicircular apse and a very deep presbytery (length about 21,3 m).
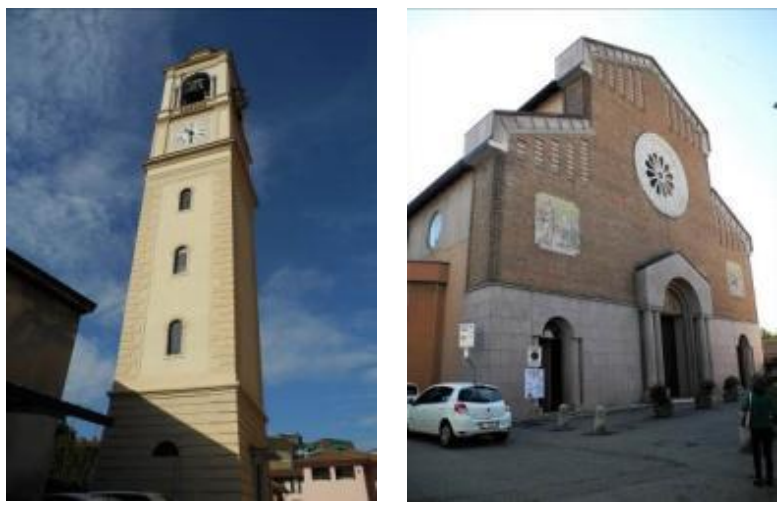

Figure 1. External views of the Church of St. Bernardino: a) The new bell tower and $b$ ) The added new façade

The naves are defined by 12 twin monolithic columns in granite, three groups per side, which support four arches at the top. The walls that define the central nave are set above the four arches and are characterized by five single-lancet windows on each side. To cover the central nave, differently from the vaulted ceiling present in the original drawings, there is a wooden coffered ceiling that continues into the presbytery and the semicircular apsidal basin (Figure 2). This change of ceiling confirms the fair to add heavy structures on the load bearing walls of the central nave during the construction.

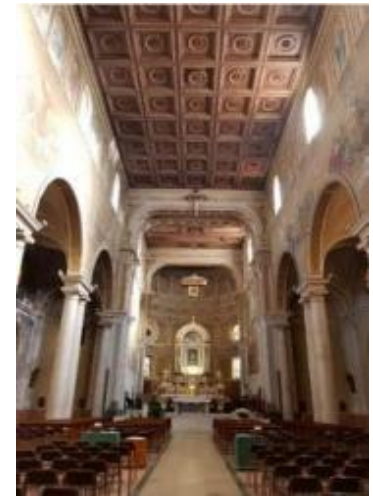

a)

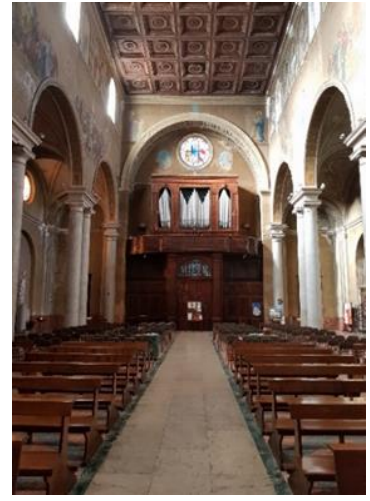

b)
Figure 2. Internal views of the church: a) towards the apse and b) towards the counter façade. The wooden ceiling is visible over the nave

Drawings and descriptions mention the presence of masonry groin vaults to cover the two aisles. However, through 
observation on-site observation and a first photogrammetric restitution (Figure 3), it has been possible to suppose that they are covered by light thin sail vaults. This masonry architecture shows the first elements realized using reinforced concrete: three rectangular beams over the central nave separating the nave from the presbytery and the apse, four semi-circular columns placed in the four corners of the central nave and the arch above the organ.

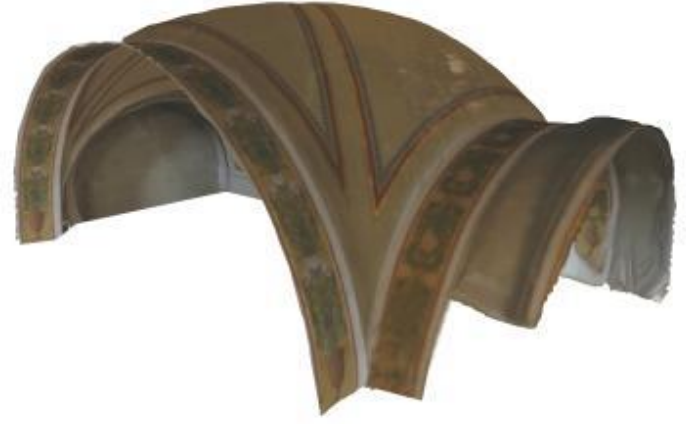

Figure 3. Photogrammetric restitution of the vault reveals that the church presents vaulted sailing ceilings

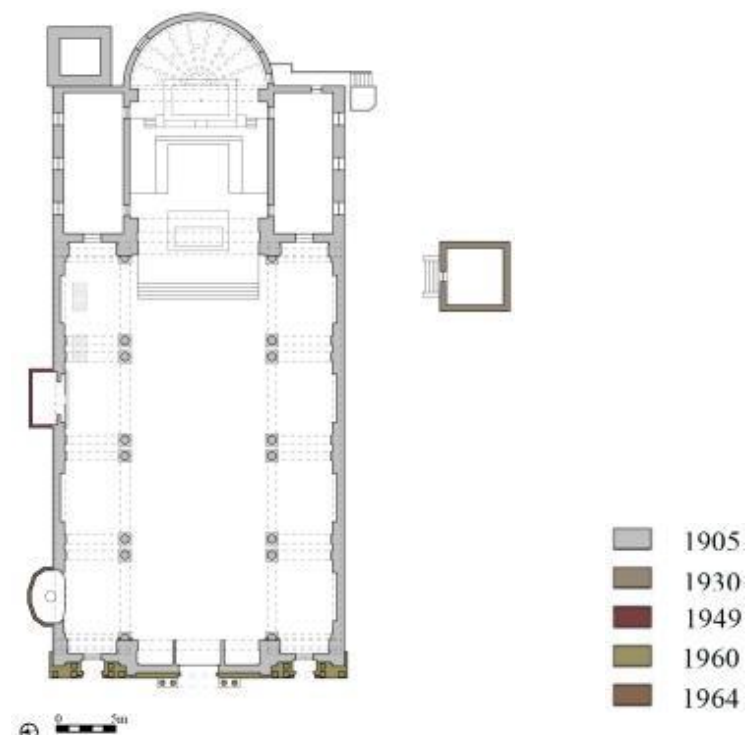

a)

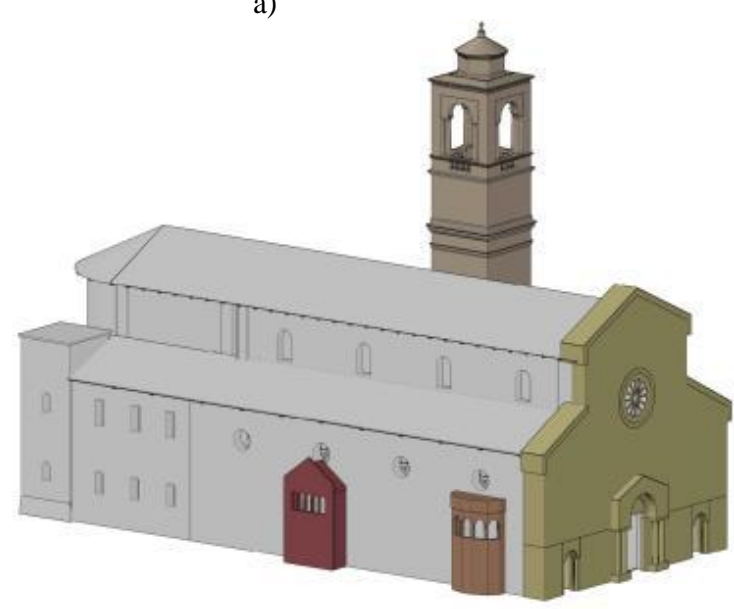

b)

Figure 4. Historical evolution of the St. Bernardino Church: a) plan and b) a three-dimensional digital model
Regarding the foundations, there are no drawings, but only general descriptions, which indicate the presence of arches under perimeter walls and 48 wooden poles under the columns. On the South side, there is the sacristy leaning against the presbytery and the new bell tower, built in 1930 and detached from the building. The new $45 \mathrm{~m}$ high bell tower follows the lines of the old bell tower, doubling its height (Figure 4).

\section{THE MONITORING SYSTEM: OBSERVED DAMAGES IN THE CHURCH DUE TO SOIL SETTLEMENT}

The integrated approach is based firstly on observations of the geometry and features of the building, so as to make appropriate modelling choices for the structure. Moreover, the inspections were fundamental in order to analyse the way the structure responds. Although the church was built at the beginning of the 1900 s, during the course of the century, it was subjected to several repairs, including the ordinary maintenance work of the roof in 2003, excluding primary structures. Other work concerned the restoration from the surface degradations of the new bell tower in 2013 .

Apart from these interventions, the church shows significant damages caused by the yielding ground. The soil settlement, in this case, has caused the cracking of the walls and the sinking and consequent inclination of the columns.

\subsection{The walls of the central nave}

The cracks in the high walls of the central nave represent the most important damage present in the church of Saint Bernardino.

By observing these lesions in figure 5, deeper cracks arise and propagate at the corners of the windows with an inclination of about $45^{\circ}$. The creation of cracks with this inclination is linked to the collapse of the head walls, in particular the façade and the walls of the presbytery.

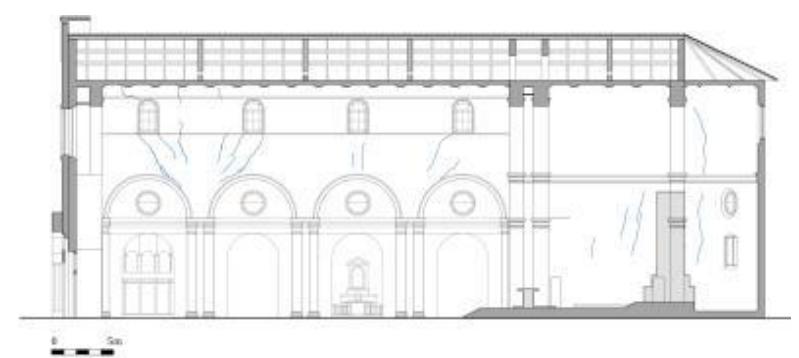

Figure 5. Longitunal section shows cracks in the wall of the nave, North side

\subsection{The perimeter walls}

The cracks in the perimeter walls are caused first of all by the constructive discontinuity in correspondence to the niches present in the walls and there are deep cracks, that propagate diagonally up to the arches of the niches (Figure 6).

After one year of monitoring, it is possible to state that the most worrying cracks are related to the second bay from the facade on the South side. At the moment small portions of plaster fall due to a continuous movement of this bay (Figure 7). 


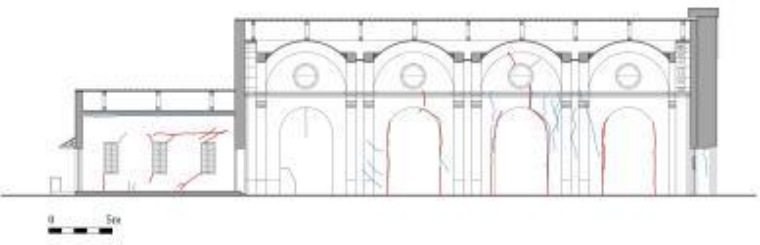

Figure 6. Section shows cracks in the perimeter, South side

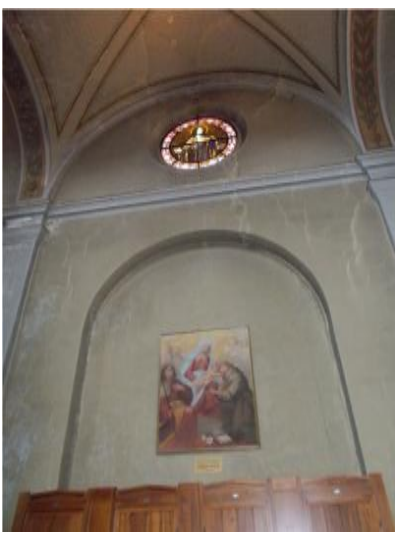

a)

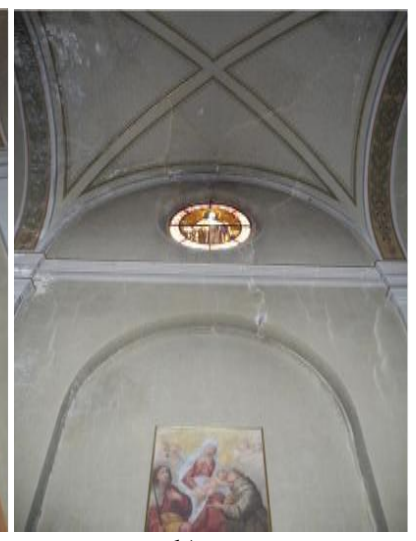

b)
Figure 7. Comparison of the cracks present on the perimeter walls of the south aisle a) cracks related to the southern bay

II and b) cracks of the southern bay II observed one year later.

\subsection{Columns settlements and leaning}

Other relevant problems regard the columns. Through an accurate observation and a basic survey, their basements present different heights: the height for basements near the facade is $12,5 \mathrm{~cm}$ and the ones near the altar are completely sunk showing 0,5 cm high. (Cardani et al. 2019).

This inhomogeneous soil settlement induces to the columns of both sides an out-of-plane rotation, with inclination towards the central nave (Figure 8a).

The more the sinking of the basements, the greater the inclination of the columns. A first measurement has been made confirming that the columns with the main out of plumb (about $12 \mathrm{~cm}$ ) are the columns near the altar, which have the lowest basements (Figures 8b, 8c).

The biggest out of plumb, that the church presents externally, concerns the new bell tower, which shows an out of plumb about $80 \mathrm{~cm}$, considering the total height of $45 \mathrm{~m}$, since 1994 .

The main cause of the damages presented is the subsidence of the soil, whose characteristics are described in the works of the PGT of the Municipality of Sesto Calende. Through reading these documents, it was possible to learn the composition of the soil: sandy silts and silty sands with clay and peat.

Moreover, the hydrogeological sections have revealed a groundwater at a depth of 5 meters from the ground level. The presence of a groundwater and its variations contribute and accentuate the settlements of the ground.

However, experimental laboratory tests revealed high settlements $(90 \%)$ in the early 6 years and their exhaustion after 60 years (Cardani, 2018).

The current risks present in the church are that of the detachment and precipitation of parts of plaster and glass from the upper windows, an effect linked to the kinematics of subsidence and to infiltrations due to the cracking of the walls. For the reasons described above, in 2016 it was decided to start a static structural health monitoring of the cracks inside the church. Six instruments were installed on the interior walls of the architecture: 3 on the North central wall, 2 on the South wall and 1 on the inside of the façade.

During these two years, the monitoring system has revealed a slight deformation. This result is comparable with the soil settlements. Given the slow and prolonged evolution of this type of failure, it has been necessary to continue monitoring for a longer period to fully assess its entity and to carry out at least two repetitions of the period.

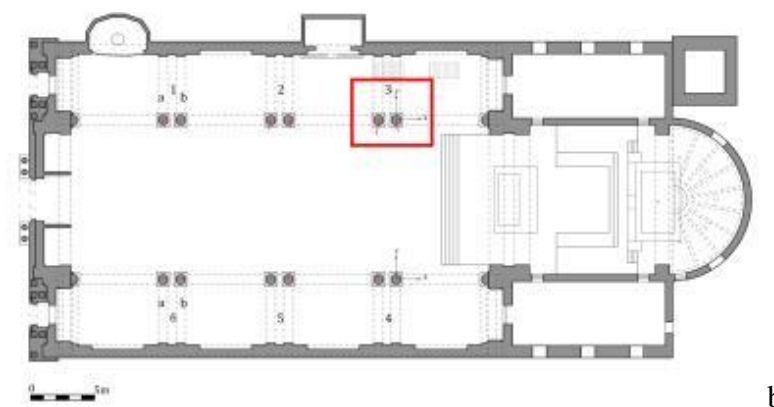

b)
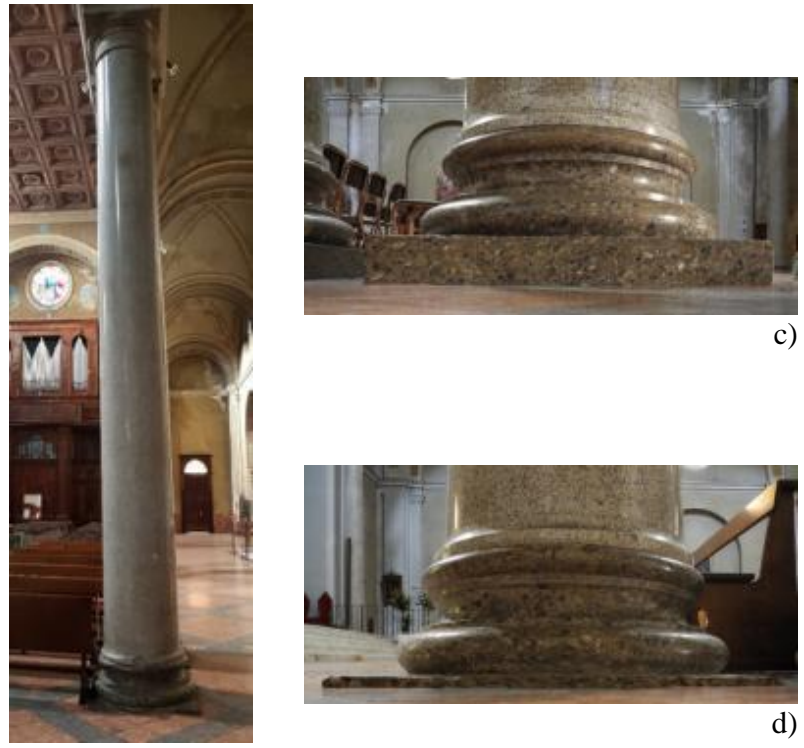

c)

Figure 8. Column inclination and sinking of basements a) Outof-plumb of the column near the altar on the North side and b) plan and c) base of the column near the façade and d) near the presbytery

\section{STRUCTURAL ANALYSIS: STATIC METHOD FOR MASONRY BUILDINGS}

The structural study is based on the following steps:

- The Limit Analysis is used to analyze a complex three-dimensional building. It allows a simple and direct representation of the results, essential in relation to the complexity of the whole system;

- For the behavior of the material Heyman's "No tension" model, (1966), is used as a failure criterion, which analyze the resistance of masonry for planeshear stress states; 
- The method of Limit Analysis is used to determine the internal forces in a settlement states as it is shown in Como (2010);

- $\quad$ Thanks to the experimental monitoring of the outward deformation and soil settlements effects on the columns, we decided to use minimum thrust solutions, among the infinite possible equilibrium configurations;

- The analysis of the damage, characterized by an accurate observation of the current crack pattern and the behavior of the structure, allows to better define the data for the structural analysis.

- The division of the structure for studying each structural element, that compose it (Figure 9).

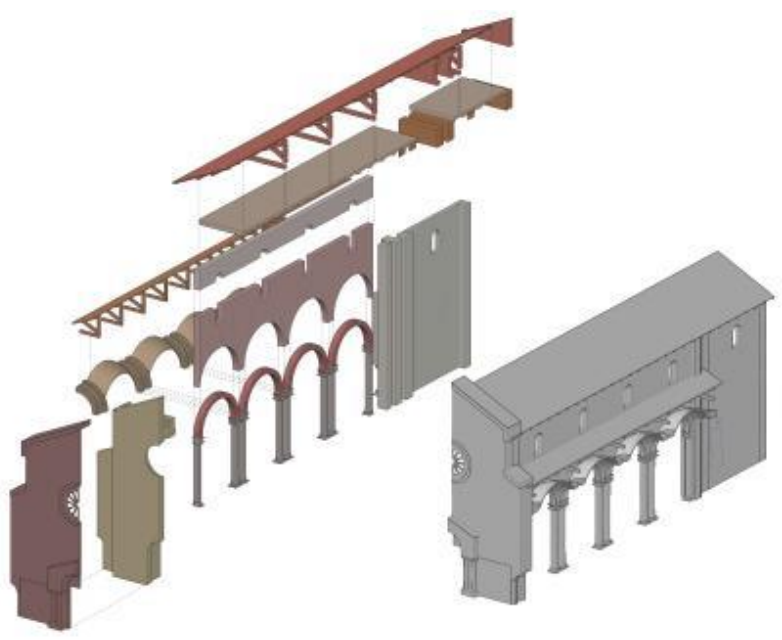

Figure 9. 3D exploded view of the analyzed system

For each one of these parts, the load analysis (including the selfweights) and the calculation of the resulting forces were carried out. The softwares adopted were first of all Excel spreadsheets, then all the calculation was checked with a code expressed with the Matlab programs. Finally, for equilibrium it considers nodal three dimensional massive zones where the above mentioned components converge.

Following the study of each component, the method was applied to the entire three-dimensional complex system of the church. Furthermore this analysis allows to grasp the interaction between the parts.

The loads are considered starting from the roof and then the structural analysis, through the static scheme, aims to obtain the resulting forces acting on the foundations.

In order to provide information on the static safety of the structure, a series of tests (described in the paragraph 5.4) is performed.

\subsection{Walls}

The wall separating the nave from the aisles represents the most complex element, for this reason the analysis provided for the horizontal division of the wall into two parts: one at the top above the single windows, and a second lower portion (Figure 10).

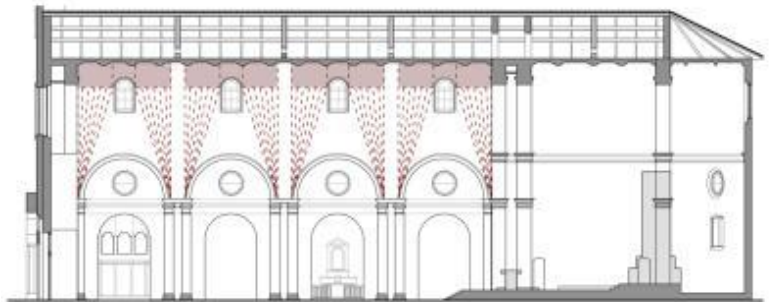

a)

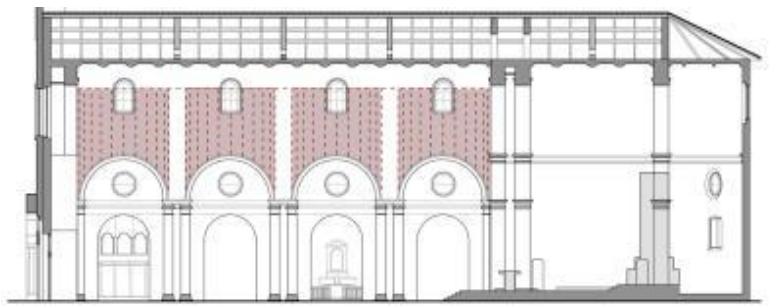

b)

Figure 10. Subdivision of the main wall in two horizontal portions: a) Upper band of the wall and b) Lower part of the wall

5.1.1 Top band of the wall: Primarily the top part corresponds to the portion of wall included between the central covering skewback and the arches skewbacks of the single-windows (Figure 10a).

This part was considered as a free body, which in addition to its own weight, supports the load of the central roof. The total load is transferred through the "centered fans" up to the top of the columns (Figure 5). The load transfer scheme is based on the cracks arranged like a centered fan above the columns. The cracks observed, corresponding to the transferring of the weight of the upper band wall to the columns, are pronounced, due to the soil settlements.

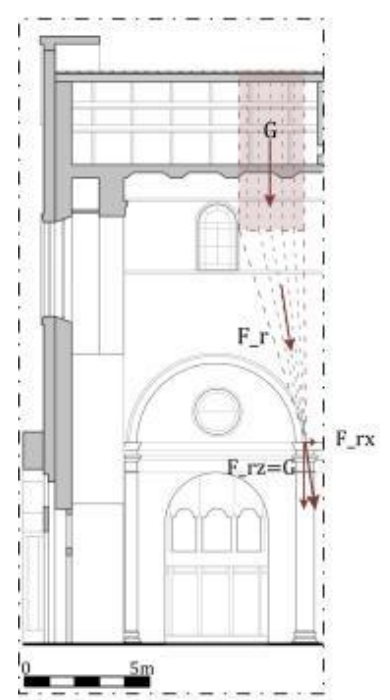

Figure 11. Use of the centered fan for the upper band

The combination of the upper part of the wall and the fans forms natural discharge arches, transmitting the weight diagonally, to the pulvini.

The inclined forces acting on the pulvini are characterized by a vertical component corresponding to the load and by a horizontal component resulting from the shear stress, born with 
the radial stress of the fan (Figure 11). It is important to note that the radial forces meet in a nodal support area with triaxial stress in which the longitudinal arches, the transverse arches, the filling of the vault and the column meet.

5.1.2 Lower part of the wall: Unlike the first part, the lower portion of wall was analyzed starting from the current cracked state, rather than from an initial configuration without damages.

The observation of the diagonal cracks confirms the hypothesis of soil settlements, in particular, the cracks in figure 12 are caused by the settlement of the double façade.

The most evident cracks are those that develop below the single lancet window, where the compressive forces of the wall are lower. However, to calculate the sliding shear stresses generated by the failure of the façade, the part of the wall adjacent to the front is also included.

For the behavior of the material, a no tension solution was adopted for the stresses in the diagonally cracked masonry at the bottom interface of the arch and the wall (Figure 13a, 13b).
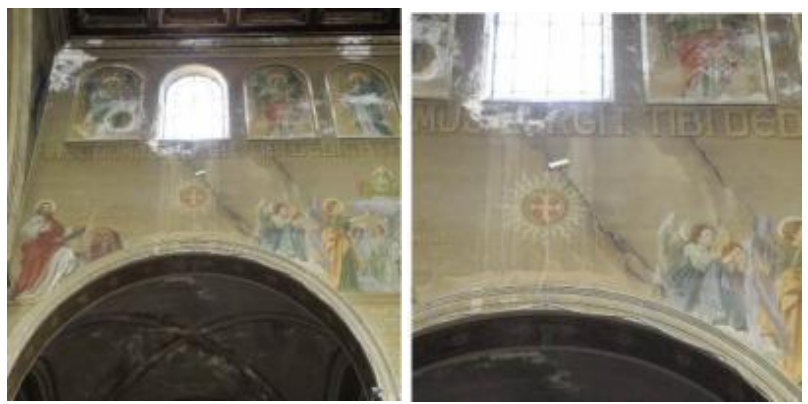

Figure 12. Images of the cracks present on the central walls, North side caused by soil settlements

After new survey that shows the actual cracks pattern, the diagonal force resultant $\mathrm{D}$ was calculated.

The diagonal force and the weight of the wall, for free body equilibrium, are balanced by a diagonal force $\mathrm{E}$ acting on the wall-façade interface (Figure 13c).

Considering that the settlement takes place at the base of the façade, thanks to to the limit analysis solution described by $\mathrm{M}$. Como (2010) the minimum reaction was calculated at that point.

To derive the minimum reaction, it is necessary to determine the maximum value of the diagonal force $\mathrm{D}$, calculated by extending the diagonal stresses state to the whole wall-arch interface to the left of the dominating shear crack below the window, down to the support close to the façade. The limit value is reached through a gradual evolution, where the support reactions change until reaching stabilised minimum values where the settlements occur.

Therefore the extension of the diagonal stress state corresponds to the limit condition.
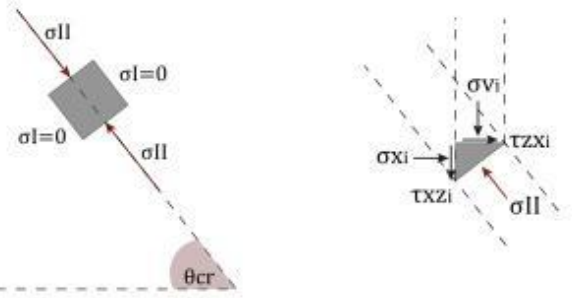

a)
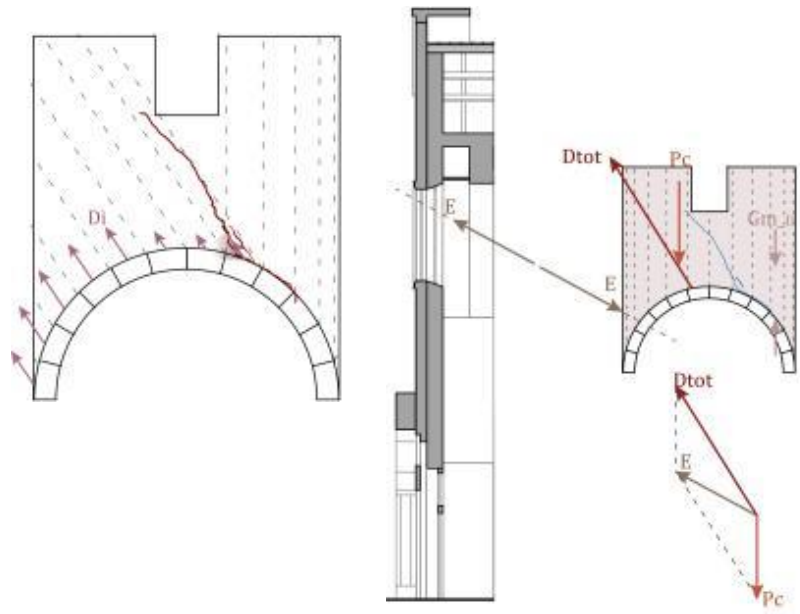

b)

c)

Figure 13. a) Diagonal stresses, according to the crack observed, obtained through the Mohr Circle, b) Diagonal stresses acting on the wall-arch interface and c) balancing force acting on the wall-façade interface

\subsection{Vaults}

The analysis continued by calculating the forces that the sail vaults of the aisles exert. The study was based on the membrane theory of the shells, which provides for the division of the vault into sections, each one agent as an independent arch, which unloads its weight to the skewbacks.

For each slice the line of thrust was determined, obtaining the corresponding reactions. In order, to obtain equilibrium for each section it is important that the line of thrust is internal to the thickness of the arch.

However, the more the end slices of the vault are considered, the more the thrust line tends to emerge from the thickness of the arch until the thickness is no longer able to guarantee equilibrium.
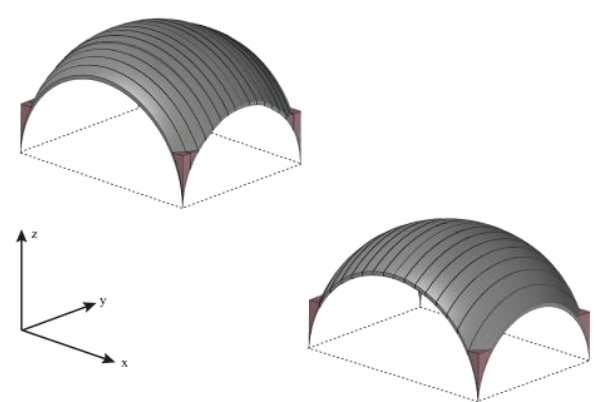

Figure 14. Subdivision of the vault in sections in the two directions X, Y

For this reason, the filling, present in the conical portion between the vault and the wall, will have the function of stabilizing mass, capable of providing a path for the line of vault thrust when it comes out of the thickness.

The dimensions of the sail vaults of the church are about $4.82 \mathrm{x}$ $6.31 \mathrm{~m}$. They have been divided into the two directions $\mathrm{X}, \mathrm{Y}$ (Figure 14). Along each axis they have been divided into 16 slices. After calculating the reactions of each portion, the resulting forces are obtained, which the vault unloads on the 
two transverse arches and on the two longitudinal arches (Figure 15).

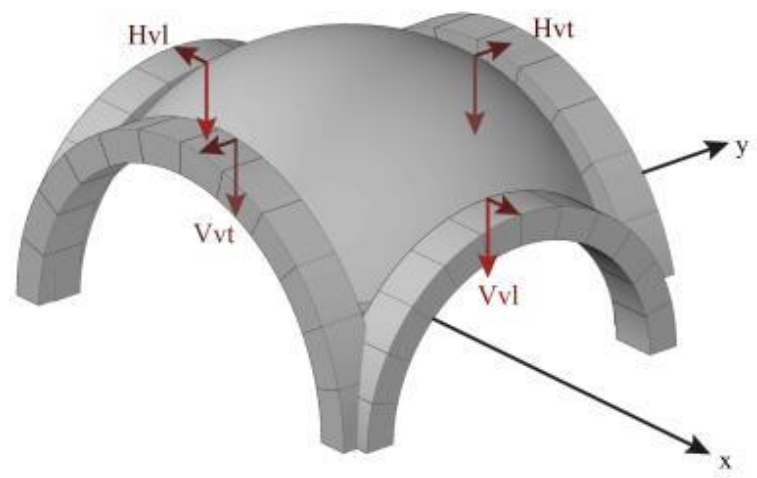

Figure 15. Forces transferred by the vault on the four arches along the perimeter

\subsection{Arches}

The research of equilibrium was made both for the longitudinal arches and for the transverse arches, which mark the bay of the aisles. The aim of the analysis is to calculate equilibrium, searching the thrust line remaining within the thickness of the arch, and choosing, among infinite solutions, the one that minimizes the reactions to the skewbacks.

Unlike the transverse arches, loaded only with their own weight, the four longitudinal arches, supporting the walls of the central nave, are loaded in addition to their own weight, also with the masonry portion below the single-light windows (second lower part of the wall, above discussed) and the diagonal resulting force D (Figure 16a). Calculating the equilibrium of the arch, the line of thrust determined comes out of the geometrical contour of the arch. The line intersects the contour of the arch in two points representing two hinges (Figure 16b), which the arch can develop in the limit condition of settlement states. Since there are no cracks observed in the arcs, the current conditions are good, therefore the limit condition has not yet been reached.

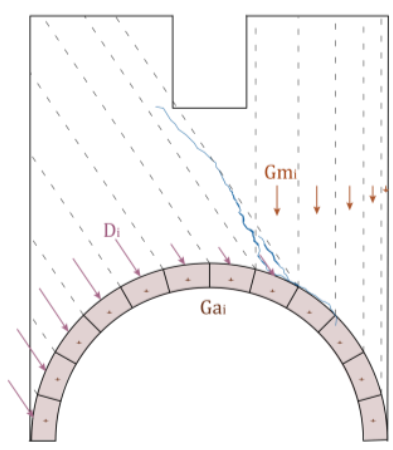

a)

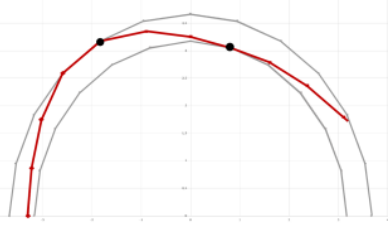

b)
Figure 16. a) Arch of the nave and b) limit condition of the pressure curve corresponding to the arch of the central nave

\subsection{Stability checks}

The aim of the study is to verify the stability of the façade and the presbytery wall, their being subjected to the overturning effects of the lateral thrusts.

Through the approach described in the text by Giuriani (2012), it has been evaluated whether the stabilizing effect of weight could resist the overturning effect of the lateral thrusts.

This is a first evaluation in which infinite compressive strength is considered and the use of mean values of the loads is based on the survey carried out on geometry and materials.

The stability analysis requires the calculation of safety coefficients obtained as the ratio of stabilization and overturning effects and verifies that the calculated value is greater than the minimum value equal to 1 , corresponding to the incipient collapse.

The observation of the damage in the church and the new survey does not reveal an overturning of the façade. This is evidenced by the shear cracks, present in the walls of the central nave and in the vaults near the front, the most cracked in the church, caused by a settlement of the façade. By determining the safety factors for the limit condition, greater values were obtained than the minimum required value; the settlement effects here are larger than in the current state, where limit conditions are considered not to be reached as yet and hence the safety coefficient is larger (Figure 17).
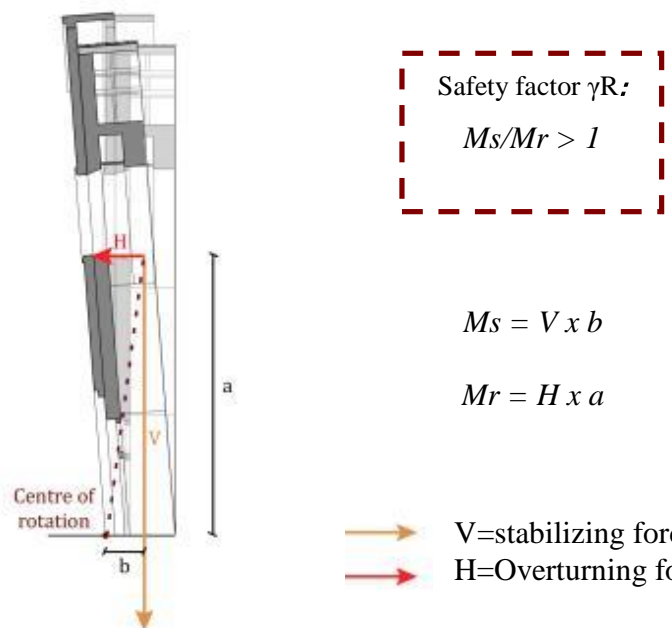

Figure 17. Test of the façade overturning, with calculation of the safety factor $\gamma R$
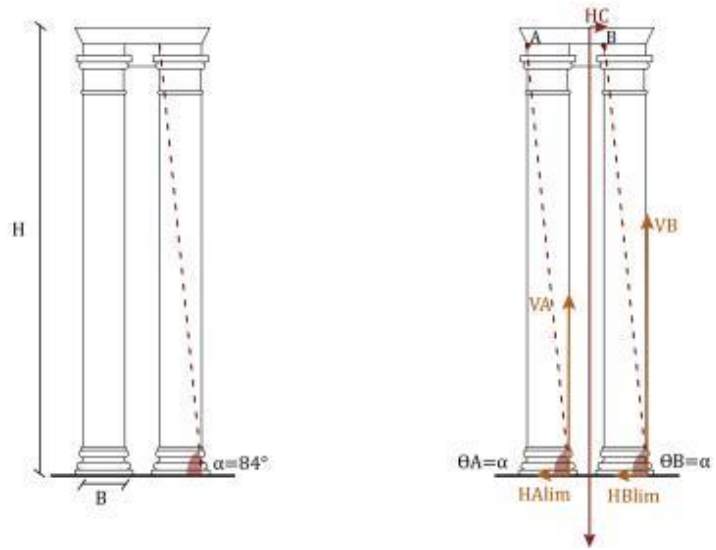

Figure 18. Columns analysis: a) Column limit inclination and b) Horizontal limit reactions at the base of the columns 
The analysis involved not only the head walls, but also the columns. The study includes two checks (Figure 18): - the first check will look for the limit slope that the forces acting on the columns can have. By checking the forces acting on the North side columns, higher values above the minimum required value of 84 degrees are obtained (figure 18a); - the second check regards the horizontal limit reactions at the base of the columns.

Figure $18 \mathrm{~b}$ shows the vertical forces $\mathrm{V}_{\mathrm{A}}$ and $\mathrm{V}_{\mathrm{B}}$ equilibrate $\mathrm{H}_{\mathrm{C}}$ and $\mathrm{V}_{\mathrm{C}}$. The analysis seeks to verify that the sum of the limit reactions at the base is greater than the real value of the thrust $\mathrm{H}_{\mathrm{C}}$ acting at the top of the column.

The checks were necessary to confirm that the current conditions of the columns, the façade and the wall of the presbytery are in favour of security.

A comparison was made between the values determined by the structural analysis and the data obtained from the static structural monitoring, after two years. It's possible to reaffirm that the deformations of the structure happen very slowly and guarantee the validity of the study of equilibrium with respect to the non-deformed configuration.

\section{CONCLUSIONS}

An application of the integrated approach in the study of the state of safety of the Church of Sesto Calende is shown.

Concerning the results about the buildings:

- After the observation of the cracks the structure was analyzed starting from the current damage state, modelling the state of stress in the walls based on this data.

- The set of analyses allows to describe a picture of the response, and to propose reflections on probable evolution but continuous monitoring of results will be integrated with diagnostic investigations, to understand the morphology and the state of conservation of the foundations of the building and the new façade and of the other parts of the church, for which no drawings have been found.

Foundation settlements is recognized as an issue since it leads to damage in the structure, which can be recognized when looking at the crack pattern. Moreover, an accurate structural analysis should be used to check the load-bearing capacity avoiding the risk of collapse and in general loss of equilibrium, in such a case retrofitting intervention should be pertained.

Concerning the results about the integrated approach method:

- The analysis was carried out with the static method of limit analysis, integrated with observations in settlement states, applied to a real structure.

- The method of limit analysis is not new but is used here to show its effectiveness in a complex system with a geometry studied in three-dimensions; there are few works like this today. - The minimum reaction theorem has been applied to determine the limit configuration as a development of the actual configuration observed.

- The analysis allows an evaluation of the conditions of the structure and can be used to determine the types of necessary intervention.

- The results obtained with limit analysis can be compared with the ones obtained with more advanced numerical analysis (FEM);

For the behavior of the material the assumptions of no tension and infinite compression strength with no block sliding were used within a static approach. Additional developments of the proposed method are to carry out the analysis considering limited material strength e.g. using the modified Mohr-Coulomb criterion.
Static analyses were synthesized in an algorithm, which allowed the formulation of a code. the whole system was parameterized, by combining the Matlab programs written for the equilibrium of all the calculated parts in an optimization algorithm. This made it possible control the sensitivity of the structural system to possible variations in the building, such as modification of material weights or parametric geometric variations. It will serve for future analysis of the church, but by varying the initial parameters, it can also be adopted for the analysis of similar cases.

\section{ACKNOWLEDGEMENTS}

The authors wish to thank don L. Ferè for his availability, and Tecnoindaginis.r.l. for the monitoring.

\section{REFERENCES}

Cardani, G., 2018. Cedimenti e dissesti strutturali della chiesa di San Bernardino a Sesto Calende: ricorsi storici. Prato, Saonara.

Cardani G., Coronelli D., Cortinovis N., Damage analysis of an early 20 th century masonry church due to soil settlement, 13NAMC, $13^{\text {th }}$ North American Masonry Conference, 16-19 June 2019, Salt Lake City, USA (to be pubblished).

Como, M., 2010. Statica delle costruzioni storiche in muratura: archi, volte, cupole, architetture monumentali, edifici sotto carichi verticali e sotto sisma. ARACNE editrice, Roma.

Giangregorio M.C., Cardani G., Coronelli D., A quest for the structural response trhough geometric representation of the design of built heritage, ICGG2018, $18^{\text {th }}$ International Conference on Geometry and Graphics, 3-7 August 2018, Milan.

Giangregorio M.C., Angjeliu G., Coronelli D., Cardani G., A study of the apse of the cathedral of Milan, 10thIMC, $10^{\text {th }}$ International Masonry Conference, 9-11 July 2018, Milan.

Giuriani, E., 2012. Consolidamento degli edifici storici. UTET, Milano.

Heyman, J.,1997. The stone skeleton, structural engineering of masonry architecture. Cambridge University Press, Cambridge. 